\title{
Sistemas municipais de cultura: caminhos possíveis para o exercício dos direitos culturais?
}

\author{
Sistemas municipales de cultura: ¿posibles caminos para el ejercicio \\ de los derechos culturales?
}

\author{
Municipal systems of culture: possible paths for the exercise of \\ cultural rights? \\ Fernanda Laís de Matos \\ Vânia Maria Andrade Brayner Rangela \\ Cristina Maria do Vale Marques ${ }^{1}$
}

\author{
Palavras chave: \\ Plenos exercícios dos \\ direitos culturais \\ Sistema Nacional de \\ Cultura \\ Sistemas Municipais de \\ Cultura \\ Autonomia federativa
}

Resumo:

O presente artigo apresenta como tema a garantia dos direitos culturais por meio da instituição de Sistemas Municipais de Cultura (SMCs), no âmbito da proposta do Sistema Nacional de Cultura (SNC). A pesquisa analítico-descritiva teve como base a inauguração, pela Constituição Federal de 1988, de paradigmas, como o da inclusão do Município na organização governamental brasileira e o do reconhecimento da fundamentalidade dos direitos culturais. Por meio da apresentação da proposta de estruturação, institucionalização e implantação de SNC, partiu-se para a análise da natureza das políticas públicas de cultura que darão base para os sistemas municipais e do conceito de autonomia federativa. Concluiu-se que, na autonomia municipal, podem ser encontradas justificativas para diferentes níveis de desenvolvimento dos SMCs. 


\section{Resumen:}

En este artículo se presenta el tema de la garantía de los derechos culturales mediante la creación de Sistemas Municipales de Cultura (SMCs), bajo la propuesta del Sistema Nacional de Cultura (SNC). La investigación analítica-descriptiva se basa en la inauguración, por la Constitución Federal de 1988, de los paradigmas, como la inclusión del municipio en la organización del gobierno brasileño y el reconocimiento de la fundamentalidad de los derechos culturales. Con la presentación de la propuesta de estructuración, institucionalización e implementación de los sistemas SNC se empezó el análisis de la naturaleza de las políticas públicas culturales que basarán los sistemas municipales y el concepto de la autonomía federal.
Palabras clave:

Pleno ejercicio de los derechos culturales

Sistema Nacional de Cultura

Sistemas Municipales de Cultura

Autonomía federal

\section{Keywords:}

The exercise of cultural rights

The Brazilian National Cultural System

Municipal Cultural Systems

Federative autonomy

\section{Abstract:}

The possibility of exercising cultural rights with the institutionalization of the so-called Municipal Cultural Systems (MCSs), in the sphere of the Brazilian National Cultural System (BNCS) is the theme of the present article. The analytical and descriptive research started with the study of two paradigms established by the Federal Constitution of 1988: the inclusion of the figure of the Municipality within the Brazilian governmental organization and the recogniztion of the fundamentality of cultural rights. Having presented the BNCS's structuring, institutionalization and implementation proposal, the nature of the public policies which will support the Municipal systems and the concept of federative autonomy were analysed. The main conclusion of this work is that different arguments, within the different dimensions of the Municipality's autonomy, explain the various levels of development of the MCSs. 


\section{Sistemas municipais de cultura: caminhos possíveis para o exercício dos direitos culturais?}

\section{Introdução}

Patrice Meyer-Bisch (2011, p. 2830) apresenta três desafios filosóficos para os direitos culturais: o primeiro, de natureza antropológica (vinculação); o segundo, de filosofia política (centralidade da cultura na política) e de filosofia do direito (subjetividade) ${ }^{2}$. O Sistema Nacional de Cultura (SNC), incorporado recentemente à Constituição Federal, parte desse desafio, objeto da natureza de norma programática desse sistema, para desenvolver sistemas de cultura, em todos os entes federados. Espera-se que, com a uniformização e a harmonização das estruturas institucionais, presentes na atual proposta do sistema (2011b, p. 41), os Estados, o Distrito Federal e os Municípios avancem na promoção da cidadania cultural, mas paira a dúvida se terão condições e meios de a garantir.

Pouco antes da apresentação da proposta do SNC, o Brasil chamou atenção do Conselho Econômico e Social das Nações Unidas (ECOSOC), no momento em que o órgão solicitou dois relatórios a respeito da implantação do Pacto Internacional dos Direitos Econômicos Sociais e Culturais ${ }^{3}$ no país (ONU, 2001; ONU, 2003). Nas duas ocasiões, o conselho emitiu preocupação em relação às desigualdades de acesso à cultura em Estados e Municípios. Por o sistema político no Brasil se organizar em função de pacto federativo, com três entes diferentes (União, Estados e Distrito Federal e Municípios), chegou a afirmar que seria necessário listar as medidas adotadas por cada um deles, mas que relatório semelhante seria inviável (ONU, 2008, p. 9). No documento mais recente (ONU, 2009, p. 11), foi reco- mendado que o Estado brasileiro tomasse medidas para encorajar participação mais expressiva de cidadãos na vida cultural dos entes federados.

Essa preocupação também é encontrada no parecer à aprovação da Proposta de Emenda Constitucional (PEC) $n^{\circ}$ 34 , de 04 de julho de $2012^{4}$, da então relatora da Comissão de Constituição e Justiça ${ }^{5}$, Marta Suplicy:

Tão importante quanto reconhecer os avanços dos últimos anos no âmbito da facilitação do acesso às fontes da cultura é reconhecer que a atuação do poder público tem sido limitada pela ausência de um sistema que articule as ações culturais dos três níveis de governo. Quando são analisadas as medidas implementadas - na forma de planos, programas e projetos - nas três esferas de governo, percebe-se que iniciativas desarticuladas comumente resultam em perda de eficiência e desperdício de recursos (BRASIL, 2012, p. 2-3). [grifos nossos]

Se, como José Márcio Barros (2009, p. 63) afirma, as políticas culturais precisam de territorialidade e setorialidade - para atender à dimensão antropológia da cultura e aos modelos de organização de circuitos produtivos culturais -, parece que é no Município que elas mais poderão aproximar-se do cidadão. Nas páginas seguintes, portanto, serão levantadas questões atinentes ao desenvolvimento dos Sistemas Municipais de Cultura (SMCs) e a promoção e a proteção dos direitos culturais.

\section{Direitos culturais, políticas públicas de cultura e Sistemas Municipais de Cultura}

Em 1966, isto é, durante a Guerra Fria, a Assembleia-Geral das Nações 
Unidas adotou o Pacto Internacional de Direitos Econômicos, Sociais e Culturais (PIDESC) como instrumento jurídico, no âmbito da Carta Internacional de Direitos Humanos, para a promoção e a proteção específica a esses direitos. Já nesse documento, afirmava-se que o Estado que aderisse à norma deveria tomar medidas para o pleno exercício dos direitos de: "a) participar da vida cultural; b) desfrutar o processo científico e suas aplicações; c) beneficiar-se da proteção dos interesses morais e materiais decorrentes de toda a produção científica, literária ou artística de que seja autor" (art. 15 , $\S \S 1^{\circ}$ e $2^{\circ}$ ). O Brasil aderiu ao PIDESC ${ }^{6}$ somente em 1992, num contexto de retomada de compromissos jurídico-políticos com a agenda internacional de direitos humanos.

O Comitê de Direitos Econômicos, Sociais e Culturais (CDESC), criado como órgão do Sistema das Nações Unidas, para monitorar o PIDESC, analisou a natureza das obrigações decorrentes do art. $2^{\circ}, \S 1^{\circ}$ do pacto. Adotou, em seguida, tipologia para as obrigações decorrentes do tratado. As medidas a serem adotadas pelos Estados, para efetivar os direitos culturais, devem incluir:

(a) respeitar os direitos econômicos, sociais e culturais, por meio não-intervenção no gozo dos direitos culturais;

(b) proteger os direitos econômicos, sociais e culturais, por meio da prevenção de violação a esses direitos por terceiros; e

(c) realizar (promover, facilitar e prover) os direitos econômicos, sociais e culturais, por meio medidas legislativas, administrativas, orçamentárias, judiciais e outras adequadas à plena fruição desses direitos (ONUCESCR, 1991). [tradução livre; grifos nossos]
O Estado brasileiro, portanto, deve pautar-se minimamente nesses documentos internacionais, na consecução de ações para garantir o pleno exercício dos direitos culturais, uma vez que foram incorporados, na década de 1990, ao chamado ordenamento jurídico brasileiro.

\section{a. Novos paradigmas da Constitui- ção da República Federativa do Brasil (1988)}

Decorrentes da abetura do processo de redemocratização do Brasil, a partir de 1985, e da realização da Constituinte de 1988; algumas transformações da ordem jurídico-política nacional parecem essenciais ao debate do exercício dos direitos culturais nos Municípios. A primeira e talvez mais radical das inovações foi a inclusão do Município na lista dos entes federados que conformam a federação brasileira. Essa mudança, por si, representa desafio substancial de gestão pública, uma vez que os atuais de 5.570 Municípios foram dotados de autonomia.

Poder-se-ia deduzir que a atual ordem jurídica do Brasil passou a reconhecer os poderes locais. Isso foi materializado por meio da inclusão do Município entre os entes que têm competências constitucionais. Pelo art. 23 da norma fundamental, o Município passou a exercer competências comuns. Dalmo Dallari (2006, p 67) lembra que há referência aos Estados somente quando se admite a legislação suplementar. Ele lembra que tem sido consenso na doutrina que essa foi uma imperfeição da Constituição, já que o Município legislará sobre a matéria em relação à qual for exercer concretamente a competência, sobretudo porque, pelo art. 30 , I, ao Município também foi conferida competência para legislar sobre os assuntos de interesse local. 
A segunda novidade refere-se à ampliação do reconhecimento histórico dos direitos culturais. Em entrevista a Teixeira Coelho (2011, p. 19), Farida Shaheed pondera que constituti desafio traçar linha divisória entre os direitos culturais, por estarem intimamente interligados aos demais direitos. Talvez, por esse motivo, seja curioso notar que os direitos culturais não encontram tipologia ou rol expresso na Constituição Federal; pelo contrário, estão espalhados ou sugeridos nela. José Afonso da Silva (2001, p. 51-52) ${ }^{7}$, Marilena Chauí (2006, p. $70-71)^{8}$, Bernardo Machado (2007, $6-12)^{9}$ e mais recentemente Eduardo Pinto (2009, p. 99-103) ${ }^{10}$ propuseram enumeração dos direitos culturais, decorrentes da Constituição Federal.

Francisco Humberto Cunha FiIho (2011) recomenda que, em vez de os direitos culturais serem pensados por meio de um rol, poderiam ser reconhecidos em diferentes categorias. Eles poderiam, em seguida, ser materializados e garantidos pelo Estado por meio de diferentes políticas culturais nestas categorias. Propõe, dessa forma, que o rol de direitos culturais exposto por José Afonso da Silva seja interpretado por meio de categorias.

Esse jurista cearense já havia anteriormente (CUNHA FILHO, 2004) oferecido contribuição para o fortalecimento do debate a respeito dos direitos culturais, ao pugnar pela interpretação de que esses direitos são traduzidos como direitos fundamentais nos arts. 215 e 216, da Constituição Federal. Os direitos culturais, com isso, traduziriam características de direitos fundamentais: seriam universais e absolutos, apresentariam historicidade, seriam inalienáveis e indisponíveis, estariam constitucionalizados, vincular-se-iam aos três poderes e teriam aplicabilidade imediata (MENDES; COELHO; BRANCO, 2010). Talvez mais importantemente, o reconhecimento da fundamentalidade implique a determinação de garantias.

Cunha Filho (2011, p. 124), em outra publicação, anota que "no Brasil é relativamente fácil reconhecer normativamante novos direitos; difícil mesmo é dar efetividade a eles". Assim como no caso dos direitos, categorizar as garantias seria mais importante para proteger e promover os direitos culturais do que elaborar rol taxativo deles. Esse foi 0 caso de outras áreas dos serviços públicos: a chamada Carta Magna brasileira também resultou na criação de sistemas de organização dos mais diferentes setores da sociedade nacional, os quais são necessariamente apoiados no princípio da descentralização (CUNHA FILHO, 2010, p. 13).

A ideia do SNC, como se verá, provém desse impulso. Exemplos significativos, no que se refere à garantia de direitos sociais, são o Sistema Único de Saúde (SUS), o Sistema Único de Assistência Social (SUAS). O primeiro modelo seria o mais significativo para o SNC, especialmente no que diz respeito à descentralização de recursos, à democratização de políticas públicas e à municipalização das ações ${ }^{11}$.

Em busca de vincular as presentes e futuras gestões ao compromisso de promoção da cidadania cultural e de conferir eficácia ao art. 215, CF, levou-se conjunto de propostas legislativas ao Congresso Nacional. Após anos de debate, algumas foram aprovadas, como três emendas constitucionais - a EC $n^{\circ}$ 42, de 19 de dezembro de 2003 (que faculta aos Estados vincular receita tributária para o financiamento cultural); a EC $n^{\circ} 48$, de 10 de agosto de 2005 (a qual prescreveu que a lei estabeleceria uma "política nacional cultural, de duração plurianual, visando ao desenvolvi- 
mento cultural do país e à integração das ações do Poder Público, de acordo com prioridades"); e, mais recentemente, com impacto mais expressivo para este trabaIho, a EC n $71 / 2012$ (que criou o SNC) e diversas leis federais - a Lei $n^{\circ} 12.343$, de 02 de dezembro de 2011 (que institui o PNC e o Sistema Nacional de Informações e Indicadores Culturais - SNIIC); a Lei 12.761 , de 27 de dezembro de 2012 (que instituiu o Programa de Cultura do Trabalhador e criou o Vale-Cultura) e da Lei $n^{\circ} 13.018$, de 22 de julho de 2014 (pela qual se instituiu a Política Nacional de Cultura Viva) ${ }^{12}$.

\section{b. A proposta do SNC}

O documento "A imaginação a serviço do Brasil" (COLIGAÇÃO LULA PRESIDENTE, 2002), programa de governo do então candidato à presidência, Luís Inácio Lula da Silva, é considerado o primeiro registro da proposta do SNC. Discutido, elaborado e assinado por militantes do campo da cultura, o manifesto tinha como objetivo principal qualificar a gestão cultural por meio de seis propostas ${ }^{13}$. O Sistema Nacional de Políticas Culturais (SNPC) - denominação inicialmente sugerida - foi inserido no terceiro objetivo, o da gestão democrática.

Duas características do chamado SNPC foram afirmadas naquele manifesto: que o sistema seria maneira de garantir a efetivação de políticas públicas de cultura e que ele seria condição necessária para a efetiva descentralização da política nacional de cultura. A primeira menção oficial ao SNC foi feita em discurso do Ministro Gilberto Gil ao Fórum dos Dirigentes Estaduais de Cultura, como parte do desafio de articulação federativa para a cultura: "Para responder ao desafio de transformar o MinC num efetivo articulador da política cultural, parceiro solidário dos Estados e
Municípios, estamos investindo na criação de um Sistema Nacional de Cultura" (GIL, 2003b). Na apresentação da PEC $416 / 2005$, por isso, almejava-se a instituição de um sistema que incluía expressamente, além dos sistemas estaduais, do Distrito Federal e municipais de cultura, também instituições públicas e privadas e a articulação com outros sistemas nacionais e políticas setoriais:

Art. o 216-A. O Sistema Nacional de Cultura, organizado em regime de colaboração, de forma horizontal, aberta, descentralizada e participativa, compreende:

I - o Ministério da Cultura;

II - o Conselho Nacional da Cultura;

III - os sistemas de cultura dos Estados, do Distrito Federal e dos Municípios, organizados de forma autônoma e em regime de colaboração, nos termos da lei;

IV - as instituições públicas e privadas que planejam, promovem, fomentam, estimulam, financiam, desenvolvem e executam atividades culturais no território nacional, conforme a lei;

V - os subsistemas complementares ao Sistema Nacional de Cultura como o Sistema de Museus, Sistema de Bibliotecas, Sistema de Arquivos, Sistema de Informações Culturais, Sistema de Fomento e Incentivo à Cultura, regulamentados em lei específica.

Parágrafo único. O Sistema Nacional de Cultura estará articulado como os demais sistemas nacionais ou políticas setoriais, em especial, da Educação, da Ciência e Tecnologia, do Turismo, do Esporte, da Saúde, da Comunicação, dos Direitos Humanos e do Meio Ambiente, conforme legislação específica sobre a matéria.

Enquanto tramitava a PEC do SNC; a União, por meio do MinC, deu 
continuidade à estruturação de fato do SNC, por meio da assinatura inicialmente de Protocolos de Intenção de Adesão ao SNC, posteriormente substitutídos por Acordos de Cooperação Federativa - ACFs, cujo objeto é a o estabelecimento de condições e a orientação à instrumentação necessária para o desenvolvimento do SNC, com implantação coordenada e conjunta de programas, projetos e ações, no âmbito de competência do Município, do Distrito Federal ou do Estado em questão (BRASIL, 2013). Nesses instrumentos, reforçou-se a ideia de fortalecimento de uma rede de articulação: o SNC "é um sistema de articulação, gestão, informação e promoção de políticas públicas de cultura com participação e controle social, pactuado entre os entes federados". A proposta levada ao Consellho Nacional de Política Cultural (CNPC), cuja elaboração fora mediada em oficinas, na I Conferência Nacional de Cultura e em outros espaços de debate, pelo MinC, sugeria que o SNC poderia ser definido pelas partes que o compõem, por como elas interagem e por quais propriedades Ihe são peculiares:

concluiu-se que, em relação à sua composição, o SNC reúne a sociedade civil e os entes federativos da República Brasileira - União, estado, municípios e Distrito Federal - com suas respectivas políticas e instituições culturais, incluindo os subsistemas setoriais já existentes e outros que poderão vir a ser criados: de museus, bibliotecas, arquivos, do patrimônio cultural, de informação e indicadores culturais, de financiamento da cultura, etc. (BRASIL, 2011b, p. 41) [grifos nossos]

Quando da aprovação da referida PEC, a redação final do caput do art. 216-A, CF passou a apresentar a seguinte redação:
O Sistema Nacional de Cultura, organizado em regime de colaboração, de forma descentralizada e participativa, institui um processo de gestão e promoção conjunta de políticas públicas de cultura, democráticas e permanentes, pactuadas entre os entes da Federação e a sociedade, tendo por objetivo promover o desenvolvimento humano, social e econômico com pleno exercício dos direitos culturais. [grifos nossos]

$O$ art. 216-A, tema da EC $n^{\circ}$ $71 / 2012$, além de ter instituído o SNC, incluiu na Constrituição Federal a definição, o objetivo, os princípios, a estrutura e a forma de regulamentação dele. Apresenta, por isso, conteúdo programático e está associado à elaboração de diretrizes, metas, programas pelo Estado, os quais devem ser cumpridos pelo Poder Público. Cunha Filho (2011, p. 123) alerta que o esse caráter programático significa que os direitos culturais podem ser realizados por meio de diferentes projetos políticos. Isso também significa que depende de atuação legislativa e política futura do poder público, para que possa produzir os efeitos essenciais planejados inicialmente pelo constituinte (SILVA, 2001).

Superados os esforços pela inclusão do SNC e suas diretrizes gerais na Constituição Federal, restou determinado, no $\S 3^{\circ}$, que caberá à União regulamentar o sistema e pormenorizar as regras que valerão a todos os integrantes desse sistema. Como se trata de matéria de cooperação federativa, a espécie legislativa a ser editada deve ser a da lei complementar. O Projeto de Lei Complementar (PLC) foi elaborado pelo MinC em 2012, com base no documento "Proposta de estruturação, institucionalização e implementação do Sistema Nacional de Cultura" (BRASIL, 2011b), documento aprovado em 2007 pelo 
Conselho Nacional de Políticas Culturais (CNPC), resultado de discussões a respeito do SNC com diferentes setores sociais e do trabalho de três Grupos de Trabalho, compostos por especialistas convocados pela Secretaria de Articulação Institucional, órgão coordenador do SNC no MinC.

Em 2013, o projeto foi devolvido pela Casa Civil ao MinC. A reapresentação dele foi objeto, no mesmo ano, de uma das propostas mais votadas na III Conferência Nacional de Cultura (III CNC) ${ }^{14}$. Em 2014, a nova minuta foi reencaminhada à Casa Civil. Enquanto se aguarda a regulamentação do SNC, não há certeza se as diretrizes aprovadas pelo CNPC serão transformadas em lei.

\section{O lugar dos SMCs na proposta do SNC}

Uma das preocupações com o projeto do SNC é a que ele poderia tornar-se uma espécie de camisa de força para a cultura brasileira. Definir uma macropolítica pela qual se garanta o pleno exercício dos direitos culturais, no espaço territorial de um país continental seria temerário e não se diferenciaria da tradição centralizadora da história das políticas culturais brasileiras. Poderia significar, se os devidos cuidados não fossem tomados, a elaboração de normas gerais para os sistemas de cultura, cuja aplicação resultaria na homogeneização da diversidade cultural ou mesmo na primazia de expressões culturais específicas, em detrimento de outras.

A forma, por isso, como Cunha Filho (2010, p. 136-137) traduziu o espírito do SNC parece não se eximir dessa preocupação: o SNC deve constituir sistema misto, com características de sistemas estáticos e dinâmicos. Os pri- meiros - como no caso do SUS, principal modelo inspirador - referem-se a obrigações positivas do Estado, preveem comportamentos obrigatórios para os entes federados e têm objeto definido. Os outros propõem responsabilidades diferentes para os variados atores envolvidos. A síntese proposta pelo jurista seria um equilíbrio entre os dois modelos, dado que a cultura é campo definido pela subjetividade, pela fluidez e pela dinâmica dos processos que lhe são inerentes; mas que necessita de um ponto estável, para desenvolver políticas públicas específicas.

O núcleo estático do SNC, dessa forma, seria a estrutura básica proposta para os sistemas federal, estaduais, do Distrito Federal e municipais de cultura, compostos de nove elementos (art. 216A, $\S 2^{\circ}, C F$ ). Devem conformar os sistemas de cultura no Brasil: órgão gestor, o chamado CPF da cultura (conselho de políticas culturais, plano de cultura e sistema de financiamento à cultura), conferência de cultura, sistemas setoriais, sistema de informações e indicadores culturais, programa de formação na área da cultura e comissões integestores. Identificam-se, portanto, mecanismos de gestão de políticas públicas de cultura, instâncias de articulação e participação social, subsistemas e, diferentemente de outros sistemas, programa de formação.

O entorno dinâmico desses sistemas se constituiria da autonomia de cada ente para organizar a respectiva polítical cultural. Isso se realizaria pelas interações entre os diferentes níveis da federação e destes com os diversos setores da sociedade brasileira e pelas possibilidades de descentralização federativa. Os processos resultantes das inter-relações entre o núcleo estático com o entorno dinâmico do sistema constituiriam a qualidade distintiva fun- 
damental dele em relação às experiências internacionais ${ }^{15}$.

Como a organização dos sistemas de cultura é de competência concorrente (arts. 24, IX e 216-A, § $3^{\circ}, \mathrm{CF}$ ), à União cabe elaborar as normas gerais, e, a cada Município, instituir o respectivo sistema, por meio de leis próprias, respeitados os ditames constitucionais. Ao serem retomados os esforços de articulação, para assinatura de acordos de cooperação com Estados e Municípios, parece que o MinC evidenciou a necessidade de oferecer orientações específicas a cada tipo de ente federado. Para atender à demanda recebida, guias de orientações ao Estados e ao Municípios foram redigidos pela equipe do MinC. Na última atualização do "Guia de orientações para os Municípios: perguntas e respostas", antes de serem respondidas dúvidas frequentes recebidas pelos gestores municipais, afirma-se que:

É importante que todos os componentes do Sistema Nacional de Cultura estejam presentes nas esferas federal, estadual, municipal e distrital (à exceção das Comissões Intergestores, que fazem parte apenas das instâncias federal e estadual). No entanto, nem todos os municipios têm condições materiais, técnicas e políticas de implantar todos os componentes do SNC. Esse é o caso do Sistema de Informações e Indicadores Culturais, dos Sistemas Setoriais e do Programa de Formação na Área da Cultura, que os pequenos e médios municípios, em geral, não têm condições ou necessidade de instituir imediamente nos seus Sistemas Municipais de Cultura. Entretanto, podem e devem interagir com esses componentes nas esferas estaduais e nacional, a fim de se manterem integrados ao pro- cesso geral de implantação do SNC. (BRASIL, 2011a, p. 32).

Se a regulamentação do SNC acompanhar esse entendimento, ao Município caberá a estruturação e a implantação de cinco componentes, referidos como obrigatórios: além do órgão gestor, duas instâncias de articulação, pactuação e deliberação (conferência municipal de cultura e conselho municipal de política cultural) e dois instrumentos de gestão (plano municipal de cultura e orçamento municipal da cultura ${ }^{16}$. No que se refere ao prazo, para a instituição dos SMCs, os Municípios que aderiram ao ACFs, pactuaram que realizariam 02 anos da adesão oficial ao SNC.

\section{Dimensões da autonomia municipal no desenvolvimento dos SMCs}

Ainda que os Municípios tenham inicialmente de estruturar cinco componentes, parece fundamental considerar que serão necessários esforços de naturezas diversas, para que consigam criar os respectivos SMCs e torná-los efetivos. Dada, além disso, a discrepância entre os desafios enfrentados pelas gestões dos cerca de 5.570 Municípios brasileiros, parece razoável afirmar que não apenas ações da Administração Pública Municipal serão necessárias para promover e proteger os direitos culturais dos habitantes de cada localidade, mas verdadeiro conjunto de políticas públicas de cultura.

Numa discussão a respeito de SMCs, parece relevante compreender as especificidades das políticas públicas de cultura e quais as discussões correntes a respeito da contribuição da cultura para o desenvolvimento humano. Canclini (2001, p. 65) arrazoa que as políticas culturais - sem fazer distinção entre públicas ou privadas - resumem 
um conjunto de intervenções realizadas pelo Estado, por instituições civis ou por grupos comunitários organizados, com a finalidade de "orientar o desenvolvimento simbólico, satisfazer as necessidades culturais da população e obter consenso para um tipo de ordem ou de transformação social”. Já Botelho (2006, p. 50-51) explica que política pública para a cultura não pode prescindir de ser formulada com base em diagnóstico da realidade e em hierarquia de prioridades. Parece fundamental, portanto, que o gestor, dessa maneira compreenda ou se sensibilize dessa dimensão.

Recorre-se ainda a Bucci (2006, p. 39), para quem política pública é, na realidade, um programa de ação governamental, resultado de variados processos juridicamente regulados, que usam todos os meios disponíveis para o Estado alcançar objetivos socialmente relevantes e politicamente determinados. Ele não seria composto apenas de atos de gestão, mas de todas as etapas do processo eleitoral, do processo de planejamento, do processo de governo, do processo orçamentário, do processo legislativo, do processo administrativo e do processo judicial. Rua (1999, p. 231) acrescenta que a alocação de bens, recursos e valores públicos acontece entre os diversos atores políticos envolvidos e que o caráter público dessas políticas deriva principalmente da autoridade soberana do poder público, a qual as torna imperativas.

Ao se tratar, em decorrência disso, de direitos e políticas culturais e SMCs, parece impossível deixar de problematizar uma das principais características dos entes federados brasileiros: a autonomia. Esse termo é encontrado em poucos dispositivos constitucionais. O primeiro e talvez o mais fundamental deles é o caput do art. 18: "a organização político-administrativa da Repúbli- ca Federativa do Brasil compreende a União, os Estados, o Distrito Federal e os Municípios, todos autônomos, nos termos desta Constituição". Além desse caso, ele pode ser observado ainda nos arts. 29 e 34 , VII, c.

É curioso observar que a "autonomia dos entes federados e das instituições da sociedade civil" também constitui princípio do SNC, inscrito no art. 216-A, $\S 1^{\circ}$, VIII CF, pela EC nº 71/2014. Foi uma das poucas vezes que o princípio federalista foi reiterado no texto constitucional. Interpretação de acordo com a vontade presumida do legislador indicaria a finalidade de garantir a participação do Município no desenvolvimento do SNC. Com o intuito de investigar as repercussões desse princípio para o desenvolvimento dos SMCs, detalhar-se-á o conceito de autonomia do Município, por meio de quatro dimensões (DALLARI, 2010; MEIRELES, 2006): auto-organização, autogoverno, autolegislação e autoadministração.

\section{a. Auto-organização}

A primeira, da autoorganização, presente no caput art. 29, CF, traduz-se na autodeterminação do Município em estruturar o próprio funcionamento:

O Município reger-se-á por lei orgânica, votada em dois turnos, com o interstício mínimo de dez dias, e aprovada por dois terços dos membros da Câmara Municipal, que a promulgará, atendidos os princípios estabelecidos nesta Constituição, na Constituição do respectivo Estado (...)

A Lei Orgânica do Município (LOM) - equivalente a uma constituição municipal, deve ser elaborada pela Câmara Municipal, tem procedimento específico e qualificado para ser aprovada e 
institui regras sobre atribuições dos poderes Legislativo e Executivo municipal, competências e procedimentos administrativos, entre outros temas relevantes. É na LOM que geralmente é prevista a competência, por exemplo, para criar e extinguir os órgãos da Administração Pública Direta, como órgãos gestores de cultura. As atribuições, além disso, desses órgãos, não poderão ir de encontro às determinações da LOM. Se, por um lado, a Constituição Federal conferiu autonomia para os Municípios se organizarem, e agora poderão instituir os respectivos SMCs, por outro, a grande quantidade de Municípios pequenos tornou-se dependente de recursos do Fundo de Participação dos Municípios e seus administradores geralmente afirmam não disporem de condições para compor secretaria exclusiva de ou orçamento para a cultura.

Constitui a Meta 37 do Plano Nacional de Cultura (PNC) "100\% das Unidades da Federação (UFs) e $20 \%$ dos municípios, sendo $100 \%$ das capitais e $100 \%$ dos municípios com mais de 500 mil habitantes, com secretarias exclusivas de cultura instaladas" (BRASIL, 2012). Caso a transformação do respectivo órgão gestor numa secretaria exclusiva de cultura (caso esta ainda não exista) seja do interesse dos gestores municipais, será necessário ter a LOM como base e coordenar ações com a Câmara Municipal. Torna-se fundamental para o gestor municipal, portanto, ter ciência de que as decisões políticas traduzidas nesses e em outros dispositivos terão implicação direta na forma como o SMC será estruturado.

\section{b. Autogoverno}

A segunda dimensão da autonomia municipal, a de autogoverno, refere-se à existência de mecanismos específicos para a escolha dos representantes locais que governarão o Município em questão. No art. 29, CF, também estão dispostas as regras para a escolha dos representantes do Poder Executivo (prefeito e vice-prefeito) e do Poder Legislativo (vereadores) municipais. Decorrem dessas escolhas funções específicas: as funções administrativa e de governo cabem àquele, já as funções legislativa, deliberativa, fiscalizadora e julgadora, a este último Poder.

De acordo com o art. 29, IV, a, b e c, CF, a quantidade de vereadores a serem eleitos é determinada de acordo com um sistema de representação proporcional e partidária, com relação à quantidade de habitantes: entre nove e vinte e um vereadores, nos Municípios com até um milhão de habitantes; entre trinta e três e quarenta e um, nos Municípios com até cinco milhões de habitantes; e entre quarenta e dois e o cinqüenta e cinco, nos Municípios com mais de cinco milhões de habitantes. Como é nesta dimensão que se espelha a capacidade de os representantes municipais realizarem escolhas políticas, as decisões resultantes dela terão impacto direto nos serviços e nas políticas públicas. Conhecer as propostas dos parlamentares para o setor cultural e acompanhar as atividades legislativas poderá auxiliar a compreender as razões para que as políticas culturais locais sejam perenes ou circunstanciais naquele espaço.

\section{c. Autolegislação}

A terceira faceta da autonomia municipal, a da autolegislação, representa o poder normativo do Município, em sentido estrito. Se o princípio da legalidade (art. 37 , caput; e art. $5^{\circ}$, II, CF) é um dos corolários do direito administrativo e tem impacto direto em todos os agentes públicos, essa dimensão torna-se estratégica, porque os limites da legalidade naquele Município serão defi- 
nidos pela Câmara e, em alguns casos, pela Prefeitura e respectivos órgãos. Essa categoria apresenta implicação para a cultura, na medida em que o Município tem competência, por exemplo, de "promover a proteção do patrimônio histórico-cultural local, observada a legislação e a ação fiscalizadora federal e estadual" (art. 30, IX, CF).

Com a EC n $n^{0} 71 / 2012$, foi acrescida a competência de os Municípios instituírem os respectivos sistemas de cultura, em leis próprias. Dependerão do voto do Poder Legislativo Municipal não só a estrutura e os componentes do respectivo SMC, mas também a validação dos planos municipais de cultura, com validade de dez anos, e eventuais reformas na estrutura do SMC. A Prefeitura ou o órgão gestor de cultura, por outro lado, serão responsáveis por aprovar o regimento interno do conselho municipal de política cultural, convocar comissões organizadoras de conferências (inter)municipais de cultura, entre outras normas.

\section{d. Autoadministração}

A autonomia administrativa concerne à organização dos serviços públicos municipais. Ela tem que ver com a vinculação ou a discricionariedade (oportunidade e conveniência) do gestor municipal. A decisão, por instância, de aderir ou não ao SNC, cabe estritamente ao representante do Município, chefe do Poder Executivo local.

Outro aspecto ligado a esta dimensão é a autonomia financeira e refere-se ao modelo vigente de planejamento orçamentário-financeiro (art. $165, C F)$, pelo qual se criaram instrumentos específicos e exclusivos de planejamento orçamentário e fiscal, de qualquer dos entes federados: o Plano Plurianual (PPA), a Lei de Diretrizes
Orçamentárias (LDO) e a Lei Orçamentária Anual (LOA). As relações intergovernamentais propostas pelo SNC, a descentralização de recursos e os tão aguardados repasses de recursos recaem nessa dimensão, uma vez que a autonomia financeira as permeia.

Em outras palavras, se os SMCs forem criados - ainda que de maneira estratégica, participativa e transparente - sem inclusão de diretrizes para as políticas públicas de cultura, nesses mecanismos, os esforços envidados para a estruturação dos cinco componentes básicos dos SMCs terão grandes chances de serem esquecidos por nova gestão municipal. As políticas públicas municipais para a cultura, sobretudo, por meio dos planos municipais de cultura, podem ser fortalecidas, se integradas ao planejamento orçamentário e fiscal.

\section{Em busca de conclusões}

Ao parodiar Norberto BOBBIO (1992), pode-se dizer que a realização dos direitos culturais é desafio até mesmo à Constituição mais evoluída e põe em crise até mesmo o mais perfeito mecanismo de garantia jurídica. A institucionalilzação do SNC, por meio da referida emenda constitucional e das adesões dos entes federados, tem o condão de elevar o nível de seguranca jurídica em relação às políticas culturais em todos os recantos do país. A consolidação dele tem-se dado por meio de processo gradual de reinvindicação da plena realização dos direitos culturais, da militância cultural, como acontece em outros sistemas de descentralização de políticas sociais.

O SNC constitui projeto estruturante para organizar as políticas públicas de cultura no Brasil, cujos elementos deverão em tese fornecer diagnóstico e bases para que ele se fortaleça e se re- 
troalimente. Nesse contexto, parece que questões sobre qual é o papel do Estado no setor cultural; qual é o papel do MinC, no desenvolvimento do SNC e no apoio aos SMCs; e que cuidados devem ser tomados para que o núcleo estático não prescinda do entorno dinâmico dos SMCs estarão sempre em debate.

O protagonismo e autonomia reconhecidos e propalados desde 1988 apresentam duas faces: ao mesmo tempo em que garante o direito, aos governantes locais, de estabelecerem políticas públicas de cultura, pode por em risco a missão constitucional do Estado Brasileiro de garantir os direitos culturais. Outra questão que merece atenção é sobre quais instrumentos a sociedade civil tem para garantir o funcionamento dos Sistemas Municipais de Cultura instituídos.

As dimensões da autonomia principal apresentadas podem evidenciar, em conjunto ou isoladamente, entraves ou potencialidades ao desenvolvimento dos SMCs. Se, além disso, os Municípios têm liberdade para se administrarem, seus gestores, muitas vezes, não estão qualificados para a autogestão política da cultura. Se, por fim, conseguirem incluir na agenda governamental o tema da política cultural e Ihe derem prioridade, mas não envolverem a sociedade civil e promoverem o controle social, os SMCs dificilmente promoverão a cidadania cultural pretendida.

\section{Bibliografia}

BARROS, José Márcio Barros. Processos (trans)formativos e a gestão da diversidade cultural. In: CALABRE, Lia (org.). Políticas culturais: reflexões sobre gestão, processos participativos e desenvolvimento. São Paulo: Itaú Cultural; Rio de Janeiro: Fundação Casa de Rui Barbosa, 2009.
BOBBIO, Norberto. A era dos direitos. Trad. Carlos Nelson Coutinho. Rio de Janeiro, Campus: 1992.

BOTELHO, Isaura. Para uma discussão sobre política e gestão cultural. In: CALABRE, Lia (Org.). Oficinas do Sistema Nacional de Cultura. Brasília: Ministério da Cultura, 2006. p. 45-60.

BRASIL. Constituição da República Federativa do Brasil de 1988. Disponível em: <http:// www.planalto.gov.br/ccivil_03/constituicao/ constituicao.htm>. Acesso em jun. 2012.

BRASIL. MINISTÉRIO DA CULTURA. Minuta de Acordo de Cooperação Federativa que entre si firmam a União, por intermédio do Ministério da Cultura - MINC e o Município de I , com vistas ao desenvolvimento do Sistema Nacional de Cultura. Brasília, Secretaria de Articulação Institucional, 2013.

As metas do Plano Nacional de Cultura. Brasília: Ministério da Cultura, 2012.

Guia de orientações para os municípios: perguntas e respostas. Brasília, Ministério da Cultura, 2011a.

Plano Nacional de Cultura: diretrizes gerais. $2^{\mathrm{a}}$ ed. Texto atualizado com a revisão do Conselho Nacional de Política Cultural (CNPC Brasília: Ministério da Cultura, 2008. Disponível em: <http://www.cultura.gov.br/site/ wp-content/uploads/2008/10/pnc_2_compacto.pdf>. Acesso em: ago. 2012.

Proposta de estruturação, institucionalização e implementação do Sistema Nacional de Cultura. Brasília: MinC, 2011b. Disponível em: <http://blogs.cultura.gov.br/ snc/files/2012/02/livro11-602-para-aprovacao. pdf>. Acesso em: 02 abr 2012.

Resultado da Plenária Final da III CNC-01/12/2013. Disponível em: <http:// www.cultura.gov.br/3cnc $>$. Acesso em 20 mar. 2014.

BRASIL. SENADO FEDERAL. Parecer da Comissão de Constituição, Justiça e Cidadania, sobre a Proposta de Emenda à Constituição $n^{\circ}$ 34, de 2012 (PEC n० 416, de 2005, na origem), primeiro signatário o Deputado Paulo Pimenta, que acrescenta o art. 216-A à Constituição Federal para instituir o Sistema 
Nacional de Cultura. Relatora: Marta Suplicy. Disponível em: <http://www6.senado.gov.br/ mate-pdf/113073.pdf>. Acesso em dez. 2012.

BRAVO, Marta Elena. Políticas culturales em Colombia. In: RUBIM, Antonio; BAYARDO, Rubens. Políticas culturais na Ibero-América. Salvador: EDUFBA, 2008. p. 119-158.

BUCCI, Maria Paula Dallari. O conceito de política pública em direito. In: $\mathrm{BUCCl}$, Maria Paula Dallari (org.). Políticas públicas - reflexões sobre o conceito jurídico. São Paulo: Saraiva, 2006.

CHAUÍ, Marilena. Cidadania cultural: o direito à cultura. São Paulo: Fundação Perseu Abramo, 2006.

COELHO, Teixeira. O novo papel dos direitos culturais: entrevista com Farida Shaheed, da ONU. Revista Observatório Itaú Cultural/OIC. São Paulo: Itaú Cultural, 2011. n. 11. jan-abr. p. 15-26.

COSTA, Rodrigo Vieira. Federalismo e organização sistêmica da cultura: o Sistema Nacional de Cultura como garantia de efetivação dos direitos culturais (Mestrado em Direito). Programa de Pós-Graduação em Direito Constitucional, Universidade de Fortaleza, 2012.

CUNHA FILHO, Francisco Humberto. Cultura e Democracia na Constituição Federal de 1988: A Representação de interesses e sua aplicação ao Programa Nacional de Apoio à Cultura. Rio de Janeiro: Letra Legal, 2004.

Direitos culturais no Brasil. Revista Observatório Itaú Cultural. v. 11. São Paulo: Itaú Cultural, 2011, p.115-126.

Federalismo cultural e Sistema Nacional de Cultura: contribuição ao debate. Fortaleza: Edições UFC, 2010.

DALLARI, Dalmo de Abreu. Elementos de Teoria Geral do Estado. 29a ed., São Paulo: Saraiva, 2010.

DALLARI, Dalmo de Abreu. In: BRASIL. MINISTÉRIO DA SAÚDE. SECRETARIA DE VIGILÂNCIA EM SAÚDE. Programa Nacional de Controle da Dengue: amparo legal à execução das ações de campo - imóveis fechados, abandonados ou com acesso não permitido pelo morador. $2^{\mathrm{a}}$ ed. Brasília: Ministério da Saúde, 2006. p. 61-81. Disponível em: <http://www.saude.mppr.mp.br/arquivos/ File/dengue/dengue_amparo_legal_web. pdf>. Acesso em 20 out. 2014.

GILBERTO, Gil. Comissão de educação e cultura. Brasília, 14 de maio de 2003a. Pronunciamento do ministro Gilberto Gil na Comissão de Educação, Cultura e Desporto da Câmara dos Deputados. Disponível: <http://www. cultura.gov.br/site/2003/05/14/pronunciamento-do-ministro-gilberto-gil-na-comissao-de-educacao-cultura-e-desporto-da-camara-dos-deputados/>. Acesso em dez 2012.

Fórum dos dirigentes estaduais de cultura. Foz do Iguaçu, 19 de agosto de 2003b. Discurso do ministro Gilberto Gil no Fórum dos Dirigentes Estaduais de Cultura. Disponível em <http://www.cultura.gov.br/ site/2003/08/19/discurso-do-ministro-gilberto-gil-no-forum-dos-dirigentes-estaduais-de-cultura/>. Acesso em dez. 2012.

IBGE, Diretoria de Pesquisas, Coordenação de População e Indicadores Sociais, Pesquisa de Informações Básicas Municipais 2009. Rio de Janeiro: IBGE, 2010.

JIMÉNEZ, Luciana. Políticas culturales em México. In: RUBIM, Antonio; BAYARDO, Rubens. Políticas culturais na Ibero-América. Salvador: EDUFBA, 2008. p. 201-230.

MACHADO, Bernardo Novaes da Mata. Direitos humanos e direitos culturais. 30/03/2007. Disponível em: <http://www. direitoecultura.com.br/wp-content/uploads/Direitos-Humanos-e-Direitos-Culturais-Bernardo-Novais-da-Mata-Machado.pdf>. Acesso em 20 mai. 2014.

MEIRELES, Hely Lopes. Direito municipal brasileiro. 15a Ed. São Paulo: Malheiros, 2006.

MENDES, Gilmar; COELHO; Luís; BRANCO, Paulo. Curso de Direito Constitucional. $5^{\mathrm{a}}$ ed. São Paulo: Saraiva, 2010.

MEYER-BISCH, Patrice. A centralidade dos direitos culturais, pontos de contato entre diversidade e direitos humanos. Revista Observatório Itaú Cultural/OIC. São Paulo: Itaú Cultural, 2011. n. 11. jan-abr. p. 27-42.

PINTO, Eduardo Régis Girão de Castro. 
Princípios culturais na Constituição Federal de 1988 (Mestrado em Direito). Programa de Pós-Graduação em Direito Constitucional. Universidade de Fortaleza. Fortaleza, 2009. RUA, Maria das Graças. Análisede políticas públicas: conceitos básicos. In: RUA, Maria das Graças; CARVALHO, Maria Isabel Valladão de Carvalho (Orgs.). O estudo da política: estudos selecionados. Paralelo 15, 1999. p. 231-261.

SILVA, José Afonso da. Aplicabilidade das Normas Constitucionais. 5.ed. São Paulo: MaIheiros Editores, 2001.

Ordenação constitucional da cultura. São Paulo: Malheiros, 2001.

ORGANIZAÇÃO DAS NAÇÕES UNIDAS ONU. COMMITTEE ON ECONOMIC, SOCIAL AND CULTURAL RIGHTS - CESCR. General Comment No. 3: The Nature of States Parties' Obligations (Art. 2, Para. 1, of the Covenant). Adotado na 5 a Sessão do Comitê de Direitos Econômicos, Sociais e Culturais, em 14 de dezembro 1990 (Documento $E / 1991 / 23)$. Disponível em: <http://www. unhcr.org/refworld/docid/4538838e10.html>. Acesso em 24 nov. 2012.

ORGANIZAÇÃO DAS NAÇÕES UNIDAS - ONU. ECONOMIC AND SOCIAL COUN$\mathrm{CIL}$ - ECOSOC. Implementation of the International Covenant on Economic, Social and Cultural Rights: initial reports submitted by States parties under articles 16 and 17 of the Covenant. Adendo. Brasil. E/1990/5/Add.53. 20 nov. 2001. Disponível em: <http://daccess-dds-ny.un.org/doc/ UNDOC/GEN/G01/461/56/PDF/G0146156. pdf?OpenElement>. Aceso em 24 nov. 2012.

ORGANIZAÇÃO DAS NAÇÕES UNIDAS ONU. HUMAN RIGHTS INSTRUMENTS. Core document forming part of the reports of states parties Brazil. HRI/CORE/1/Add.53/Rev.1. 19 nov. 2003. Disponível em: <http://daccess-dds-ny.un.org/doc/UNDOC/GEN/G03/452/62/ PDF/G0345262.pdf?OpenElement>. Acesso em 24 nov. 2012.

SILVA, Adélia C. Zimbrão da. Sistemas Nacionais na Área de Gestão Pública: a Construção do Sistema Nacional de Cultura. In: I/ Congresso CONSAD de Gestão Pública, 2009, Brasília. II Congresso CONSAD de Gestão Pública, 2009.
1 Contatos, respectivamente: felais@gmail.com; vaniabrayner2012@gmail.com; crisvale.marques@gmail.com

20 primeiro desafio refere-se ao processo de realização pessoal, por meio da vinculação entre as pessoas por intermédio de obras, como o próprio corpo e a própria identidade, além de coisas, gestos, ambientes, instituições etc. O segundo demonstraria a necessidade de renunciar à ilusão de que a igualdade se faz, apesar das diferenças culturais; pelo contrário, os conceitos de equidade e de universalidade devem ser pensados conjuntamente. O terceiro, relativo ao campo da filosofia, referir-se-ia à vinculação dos direitos à subjetividade das expressões culturais.

3 Apesar de ter entrado em vigor, no plano internacional, em 1976; O PIDESC foi incorporado ao ordenamento jurídico brasileiro por meio do Decreto $n^{\circ} 591$, de 6 de julho de 1992.

4 Na origem (Câmara dos Deputados), a numeração da proposta - PEC n 416, de 16 de junho de 2005 - apresenta a referência pela qual ela é reconhecida no setor cultural. Após validada como norma jurídica, recebeu a numeração de Emenda Constitucional (EC) $n^{\circ} 71$, de 29 de novembro de 2012.

5 No dia seguinte à aprovação da referida PEC, a senadora seria nomeada Ministra de Estado da Cultura.

6 O PIDESC foi incorporado ao ordenamento jurídico por meio do Decreto nº 591 - de 6 de julho de 1992.

7 De acordo com José Afonso da Silva, os direitos culturais no Brasil, em decorrência dos art. 215 e 216, CF, seriam: a liberdade de expressão da atividade intelectual, artística, científica; o direito de criação cultural; o direito de acesso às fontes da cultural nacional; o direito de difusão das manifestações culturais; o direito de proteção às manifestações das culturais populares, indígenas e afro-brasileiras e de outros grupos participantes do processo civilizatório nacional; o direito-dever estatal de formação do patrimônio cultural brasileiro e de proteção dos bens de cultura.

8 Em decorrência da experiência da estudiosa à frente da Secretaria Municpal de Cultura de São Paulo, entende os direitos culturais como o direito de produzir cultura, o direito de participar das decisões quanto ao fazer cultural; o direito de usufruir dos bens da cultura; o direito de estar informado sobre os serviços culturais e sobre a possibilidade de deles participar ou usufruir; o direito à formação cultural e artística gratuita; o direito à experimentação e ao novo nas artes e nas humanidades; o direito a espaços para reflexão, debate e crítica; o direito à informação e à comunicação.

9 Bernardo Machado sugere que os direitos culturais sejam pensados com base em diferentes entendimentos a respeito de o que é a pessoa humana: se entendida com indivíduo, reconhecer-se-iam o direito autoral e o 
direito à livre participação na vida cultural; se entendida como a reunião dos povos, haveria o direito à identidade cultural e o direito-dever de cooperação cultural internacional. Finalmente, nas palavras dele: "A partir das lutas políticas e sociais que têm como marco o ano de 1968, os direitos culturais evoluíram de tal forma que é possível falar na emergência de um novo direito, ao qual denominamos direito à subjetividade ou à personalidade" (MACHADO, 2007, p. 10).

10 Em dissertação de mestrado de 2009, Eduardo Pinto sugere elenco de direitos fundamentais culturais, com base no texto da Constituição Federal: direitos de identidade, direitos de acesso, direitos de participação ativa e direitos de diversidade.

11 No primeiro pronunciamento à Comissão de Educação e Cultura do Congresso Nacional, o então Ministro Gil fez referência à falência desses sistemas no Brasil, não sem reconhecer que a situação da cultura era ainda mais calamitosa (GIL, 2003a). Como lembra. ZIMBRÃO DA SILVA (2009), a despeito das críticas a esses sitemas, nenhuma delas sugere a desmontagem do SUS ou do SUAS.

12 Outras propostas encontram-se em tramitação no Poder Legislativo Federal, como o Projeto de Lei (PL) $n^{\circ}$ 1.139/2007 (cujo objeto é a reforma da Lei Rouanet e a instituição do Programa Nacional de Fomento e Incentivo à Cultura - Procultura), que tramita conjuntamente ao PL n 6.722/2010; a PEC 49/2007, apensada à PEC n 236/2008, (cujo objeto é a inclusão do direito à cultura no rol dos direitos sociais do art. $6^{\circ}, \mathrm{CF}$ ); o PL 1.786/2011, apensado ao PL 1.176/2011 (cujo objeto é a instituição da Política Nacional Griô ou de Programa de Proteção e Promoção dos Mestres e Mestras dos Saberes e Fazeres das Culturas Populares); e mais recentemente, a PEC $n^{\circ} 421 / 2014$, que substituiu a PEC no 150/2003 (cujos objeto se referem à vinculação da receita orçamentária da União, dos Estados, do Distrito Federal e do Municípios ao desenvolvimento cultural); entre outras.

13 (1) Cultura como política de Estado, (2) Economia da cultura, (3) Gestão democrática, (4) Direito à memória, (5) Cultura e comunicação e (6) Transversalidades da política cultural.

14 Mais precisamente, foi a $3^{a}$ proposta mais votada no Eixo I (Implementação do Sistema Nacional de Cultura): "aprovar com urgência no Congresso Nacional Projeto de Lei Complementar (PLC) 383/2013 de regulamentação do SNC, na forma de um substitutivo, com o texto do projeto encaminhado pelo MINC à Casa Civil em 19/12/2012, resultado de um intenso e profundo trabalho técnico e político com a participação dos três entes federados e da sociedade civil, e apoiar a implantação e o pleno funcionamento dos seus componentes, em todos os níveis da Federação, considerando as seguintes questões: a) comissões ou grupos de trabalho formados por sociedade civil e poder público para monitorar e auxiliar nessa implantação e difundir suas informações; b) qualificação do acompanhamen- to do Ministério da Cultura (MinC) a esse processo; c) oferecimento, por parte do MinC, de suporte técnico e financeiro aos Estados e Municípios; d) o repasse de recursos do Fundo Nacional de Cultura para os fundos estaduais, distrital e municipais, mediante o cumprimento das exigências previstas no Projeto de Lei Complementar do Sistema Nacional de Cultura; e) criar, garantir e implantar o sistema setorial das culturas Indígenas" (BRASIL, 2014).

15 Na maioria dos países ibero-americanos, os sistemas de cultura assemelham-se ao que se chama no Brasil de Sistema MinC ou simplesmente a reunião dos órgãos da Administração Pública Federal Direta, Indireta e Fundacional. Para citar dois exemplos, (1) na Colômbia, o Sistema Nacional de Cultura é "Conjunto de instancias y procesos de desarrollo institucional, planificación y información articulados entre sí, que posibilitan el desarrollo cultural y el acceso de la comunidad a los bienes y servicios culturales según los principios de descentralización, participación y autonomía" (BRAVO, 2008, p. 133). (2) No México, em 1994 o Sistema de Información Cultural reúne "la infraestructura cultural de México (teatros, museos, casas de cultura, centros culturales, escuelas de arte y auditorios) los programas de estímulos a la creación, las revistas culturales, los festivales, medios de comunicación y grupos artísticos subsidiados" (JIMÉNEZ, 2008, p. 219). A despeito de haver iniciativas de institucionalização da política, não parece haver sistematização dos componentes: nos países ibero-americanos, a elaboração de planos para a cultura, no nível federal, aparece como tendência para orientação dos respectivos sistemas federais de cultura. No México, acordos de cooperação federativa também foram adotados, assim como sistema de indicadores culturais. Já Portugal apresenta redes setoriais, a exemplo dos sistemas de biblioteca, de patrimônio e de museus no Brasil. Na Argentina, o Plan Federal de Cultura, em 1990, já propugnava por organização federativa que enfatizasse o papel das províncias, análogas aos Estados no Brasil. O atual Plan Estratégico Nacional de Cultura sublinha a construção de um Sistema Nacional de Información Cultural. (ALBINO; BAYARDO, 2008, pp. 31, 133, 219).

16 É curioso notar que, entre as propostas aprovadas pela III CNC, encontra-se sugestão de "criar e implementar planos setoriais de cultura, nos estados, distritos e municípios instituídos no âmbito dos Conselhos Estaduais de seus respectivos conselhos de Políticas Culturais, a fim de fortalecer as especificidades locais" (BRASIL, 2014). Ainda que os sistemas setoriais não sejam obrigatórios para os Municípios, passaram a representar demanda social. 